\title{
Influência da idade dos reprodutores de codornas de postura na reprodução, na qualidade de ovos e na morfologia dos órgãos genitais
}

\section{Influence of laying quail breeder age on reproduction, egg quality and morphology of the genital organs}

\author{
Thais Cristina Carneiro'; Tatiana Carlesso dos Santos ${ }^{2 *}$; Alice Eiko Murakami²; \\ Robson Marcelo Rossi ${ }^{3}$; Jamile Corine Fanhani ${ }^{1}$; Catarina Stefanello ${ }^{1}$
}

\section{Resumo}

\begin{abstract}
A interação espermatozóide-ovo foi analisada durante a sua vida reprodutiva, em codornas de postura acasaladas com machos de diferentes idades (Coturnix coturnix sp.). O delineamento experimental foi inteiramente casualizado, em esquema fatorial $4 \times 4$ (idade das fêmeas $\mathrm{x}$ idade dos machos de codorna, 80,160,240 e 390 dias), com 10 repetições e 6 aves por unidade experimental, na proporção duas fêmeas para um macho. Foram avaliados variáveis de qualidade e produção de ovos, fertilidade, eclodibilidade e mortalidade embrionária na incubação e desempenho e qualidade dos ovos da progênie nas fêmeas oriundas da incubação. A idade dos machos não apresentou efeito significativo para nenhuma das variáveis estudadas. A idade das fêmeas teve efeito significativo para postura das matrizes, efeito quadrático $(\mathrm{P}<0,05)$ do número de espermatozóides $/ \mathrm{mm}^{2}$ da camada perivitelínica sobre o disco germinativo, em função da idade das fêmeas, com redução desse número ao longo da idade. A idade das fêmeas não teve efeito no peso do ovo, na espessura da casca, na percentagem de casca e de gema e na unidade Haugh. Já para a porcentagem de postura, houve efeito quadrático. As variáveis de incubação avaliadas de peso do pintainho, fertilidade, eclodibilidade e mortalidade, não apresentaram diferença quando analisados em relação à idade dos machos e fêmeas, assim como a qualidade dos ovos e desempenho da progênie resultante. A morfometria dos órgãos genitais de machos e fêmeas não apresentou diferença em função da idade das aves. Machos e fêmeas de codornas de postura mantêm habilidade reprodutiva até 56 semanas. A idade dos machos não exerceu efeito sobre os parâmetros reprodutivos e a utilização de machos mais jovens com fêmeas mais velhas não resultou em melhoras reprodutivas.
\end{abstract}

Palavras-chave: Camada perivitelínica, fertilidade, eclodibilidade, oviduto, testículo

\begin{abstract}
The sperm-egg interaction was investigated during their reproductive life, in laying quails mated with males of different ages (Coturnix coturnix sp.). The experimental design was completely randomized in factorial scheme $4 \times 4$ (age of the females of age x male quail, 80,160,240 and 390 days), with 10 replicates and six birds each, in proportion to two females for a male. The results showed that there was a quadratic effect $(\mathrm{P}<0.05)$ the amount of sperm trapped in the vitelline membrane of the germinal disc, depending on the age of the females, with a reduction of this number over the old. The age of the
\end{abstract}

\footnotetext{
${ }^{1}$ Discentes, Dept ${ }^{0}$ de Zootecnia, Universidade Estadual de Maringá, UEM, Maringá, PR. E-mail: thais@argroup.com.br; jamilefanhani@hotmail.com; catarinastefanello@gmail.com

2 Profs., Dept ${ }^{\circ}$ de Zootecnia, UEM, Maringá, PR. E-mail: tcsantos@uem.br; aemurakami@uem.br

3 Prof., Dept ${ }^{\circ}$ de Estatística, UEM, Maringá, PR. E-mail: rmrossi@uem.br

Autor para correspondência
} 
females had no effect on egg weight, shell thickness, the percentage of shell and yolk and Haugh unit. As for the egg production was a quadratic effect. The incubation parameters evaluated chick weight, fertility, hatchability and mortality did not differ when analyzed in relation to age of males and females, as well as egg quality and performance of the of the resulting progenies. The chick weight, fertility, hatchability and mortality did not differ when analyzed in relation to age of males and females, as well as egg quality and performance of the of the resulting progenies. The morphology of the genital organs of males and females showed no difference in the age of the birds. Males and females of laying quails maintain reproductive ability up to 56 weeks. The age of the males had no effect on the reproductive performance and the use of younger males to older females did not result in improved reproductive health.

Key words: Vitelline membrane, fertility, hatchability, oviduct, testis

\section{Introdução}

A idade é um fator adverso no sucesso reprodutivo em aves. A relação da idade com o decréscimo na reprodução é muito bem estudado em matrizes, os principais fatores são: a redução na produção de ovos (ROBINSON; HARDIN; ROBBLEE, 1990); a provável redução da habilidade de reter espermatozóides nas glândulas da junção útero-vagina, local de estocagem dos espermatozóides (FASENKO; ROBINSON; HARDIN, 1992); o declínio na habilidade de transportar esses espermatozóides para o local de fertilização e a possível redução no número de receptores para espermatozóides na superfície do oócito (BRAMWELL; MARKS; HOWARTH, 1995). Em matrizes pesadas de frango de corte, por exemplo, esta diminuição na fertilidade em matrizes velhas pode ser contornada até certo ponto pelo aumento no número de espermatozóides em inseminações artificiais ou aumentando-se o número de inseminações por intervalo de tempo (BRAMWELL; MCDANIEL, 1986; BRILLARD, 1993). Já nos galos, a redução na fertilidade está associada à redução no número de espermatozóides no ejaculado, de volume de sêmen produzido e em características físicas como redução na habilidade de monta dos mesmos (LAKE, 1989).

Particularmente nas codornas, as estratégias reprodutivas do macho envolvem a rápida produção, maturação e transporte dos espermatozóides através do trato reprodutivo, associado com uma capacidade limitada de estoque destes por longos períodos nos ductos genitais, em torno de 1 dia (CLULOW; JONES, 1982). Nas fêmeas, os espermatozóides sobrevivem por alguns dias no oviduto. Após a retirada dos machos, $45 \%$ dos ovos ainda são férteis, por no máximo 11 dias (SITTMANN; ABPLANALP, 1965).

Em relação à fecundação, a camada perivitelínica interna do ovo de aves pode ser considerada como sendo análoga à zona pelúcida de mamíferos (HOWARTH, 1992). É um revestimento protéico, em torno do ovo (BELLAIRS; HARKNESS; HARKNESS, 1963; BAKST; HOWARTH, 1977; KIDO; DOI, 1987), através do qual os espermatozóides devem penetrar e entrar no óvulo (BAKST; HOWARTH, 1977; OKAMURA; NISHIYAMA, 1978). Nas aves, após poucos minutos da fertilização, quanto o ovo entra no magno, a camada perivitelínica externa é depositada sobre a camada perivitelínica interna (BELLAIRS; HARKNESS; HARKNESS, 1963). Os espermatozóides que ficam livres no lúmen da interface infundíbulo/magno ficam presos na rede proteinácea da camada perivitelínica externa. Estes espermatozóides podem ser encontrados nos ovos após postura, distribuídos por toda a superfície da camada perivitelínica externa, descritos em galinhas (WISHART, 1987), em perus (WISHART, 1997) e em codornas (SANTOS et al., 2013). Em galinhas, o número de espermatozóides presos na camada perivitelínica externa é cerca de 10x mais que o número de buracos causados pelos espermatozóides na camada perivitelínica interna (WISHART, 1997). 
A metodologia de analisar a interação do espermatozóide com o ovo, através de ovos postos, representa uma possibilidade não-invasiva de inferir o número de espermatozóides no trato reprodutivo da fêmea, que atingiu o local de fertilização. Como os túbulos de estocagem de espermatozóides são o maior local de estoque destes, o número de espermatozóides contados que interagiram com a camada perivitelínica em ovos após postura é um indicativo do número de espermatozóides no oviduto da fêmea (WISHART; STAINES, 1999).

Particularmente sobre os aspectos reprodutivos em codornas, poucos trabalhos são descritos. Desta forma, objetivou-se avaliar o efeito da idade dos reprodutores de codornas de postura, machos e fêmeas, nas variáveis de qualidade dos ovos e de reprodução, na morfometria dos órgãos genitais e na qualidade dos ovos da progênie.

\section{Materiais e Métodos}

O experimento foi realizado no setor de coturnicultura do Departamento de Zootecnia da Fazenda Experimental de Iguatemi (FEI), do Centro de Ciências Agrárias, da Universidade Estadual de Maringá, Paraná. Todas as aves utilizadas neste experimento foram criadas desde o nascimento até a formação dos grupos reprodutores e posteriormente os pintainhos resultantes e as fêmeas de codornas resultantes dos grupos. Os pintainhos foram alojados em boxes de 2,5 $\mathrm{m}^{2}$, em cama de palha de arroz, com aquecimento por lâmpadas de infravermelho até 14 dias, luz natural a partir dos 15 dias de idade, recebendo ração de crescimento conforme recomendação do NRC (1994), com proteína bruta de $23 \%$ e 2.900 de energia metabolizável (kcal $/ \mathrm{kg}$ ). Aos 15 dias, as codornas foram debicadas e aos 35 dias, sexadas e transferidas para gaiolas de postura de arame galvanizado (158 $\mathrm{cm}^{2} /$ ave).

As aves receberam ração e água ad libitum em bebedouro tipo nipple, e comedouro do tipo calha, disposto em frente às gaiolas. A ração fornecida aos reprodutores a partir dos 35 dias foi formulada seguindo as exigências nutricionais das codornas, segundo recomendações preconizadas pelo NRC (1994) com 20\% de proteína bruta e 2.800 de energia metabolizável ( $\mathrm{kcal} / \mathrm{kg})$, com regime de luz de 17 horas de luz (natural + artificial).

Foram utilizadas 960 codornas em diferentes idades (80, 160, 240 e 390 dias) para os grupos reprodutores, sendo 640 fêmeas e 320 machos. O delineamento experimental utilizado foi inteiramente casualizado, em esquema fatorial 4 x 4 (idade das fêmeas $\mathrm{x}$ idade dos machos), com 10 repetições e 6 aves por unidade experimental (2 machos: 4 fêmeas). As matrizes de cada idade foram uniformizadas pela postura e pelo peso corporal (machos: 129,21 \pm 11,96 g, fêmeas: 170,18 $\pm 11,11 \mathrm{~g})$. Após 10 dias de adaptação dos grupos reprodutores, foram avaliados os parâmetros de incubação e a interação espermatozóide-ovo pela determinação do número de espermatozóides na camada perivitelínica de ovos férteis. O período experimental para análise da fertilidade e da interação espermatozóide-ovo foi de 20 dias.

\section{Qualidade de ovo e desempenho produtivo}

Para as matrizes foram analisados a qualidade e a produção de ovos em 4 semanas consecutivas. As fêmeas resultantes da incubação foram criadas seguindo os mesmo critérios adotados para as matrizes e transferidas aos 35 dias para o galpão de postura, com o mesmo delineamento experimental. As fêmeas foram alojadas em gaiolas galvanizadas com 5 repetições de 6 fêmeas, por unidade experimental e avaliadas quanto à qualidade de ovos e o desempenho produtivo por 4 ciclos de 21 dias, a partir de 10 semanas. Foram realizadas as analises qualitativas de percentagem de casca, altura de albúmen, gravidade específica, espessura da casca, unidade Haugh e as análises quantitativas de consumo de ração, peso dos ovos (g), produção de ovos (ovo/ave/dia), massa de ovos e conversão alimentar ( $\mathrm{kg} / \mathrm{dz}$ ovos e $\mathrm{kg} / \mathrm{kg}$ ovos).

No final de intervalo, por três dias consecutivos, 
foram avaliados o peso médio dos ovos, a altura de albúmen, o peso específico, a porcentagem e a espessura da casca dos ovos. Todos os ovos íntegros, de cada unidade experimental, foram identificados e pesados individualmente em balança de precisão digital (0,01 g), e submetidos ao teste de gravidade específica pelo método da imersão dos ovos em solução salina. Foram preparadas cinco soluções com densidades que variaram de 1,070 a 1,082 g/mL.

Posteriormente à realização do teste de gravidade específica, três ovos por unidade experimental foram utilizados para a determinação da unidade Haugh. Os ovos foram quebrados em superfície plana de vidro e medida a altura do albúmen utilizando um micrômetro digital. As mensurações, em milímetros (mm), foram relacionadas ao peso do ovo, obtendose assim a unidade Haugh:

$\mathrm{UH}=100 \log \left(\mathrm{H}+7,57-1,7 \mathrm{~W}^{0,37}\right)$, em que: $\mathrm{H}=$ altura de albúmen $(\mathrm{mm}) ; \mathrm{W}=$ peso do ovo (gramas).

\section{Desempenho de incubação}

Com o objetivo de avaliar os parâmetros de incubação em função da idade dos reprodutores, os ovos de cada unidade experimental, por tratamento, foram coletados, identificados e armazenados em ambiente refrigerado, de 18 a $20^{\circ} \mathrm{C}$, por até 5 dias. Foram realizadas duas incubações. Um total de 4609 ovos foram incubados em incubadora automática, com controle de umidade $\left(70 \%, 86^{\circ}\right.$ $\mathrm{F}$ no bulbo úmido) e temperatura $\left(37,6^{\circ} \mathrm{C}, 99,75^{\circ}\right.$ F no termômetro de bulbo seco), sendo executada viragem automática de hora em hora. Com 15 dias de incubação, os ovos foram transferidos para a câmara de eclosão, e, após 2 dias, os pintainhos foram pesados e transferidos para o galpão de cria e recria. Para cada unidade experimental, foram determinados: taxa de fertilidade, de eclodibilidade em relação aos ovos férteis, de mortalidade embrionária e o peso dos pintainhos. Ao final da incubação os ovos não eclodidos foram abertos e classificados como ovos não fecundados e embriões mortos. A mortalidade foi classificada como: mortalidade precoce, intermediária, tardia e ovos bicados (mortalidade na casca).

\section{Interação espermatozóide-ovo}

Para a análise da interação espermatozóideovo, os ovos de cada unidade experimental foram colhidos e acondicionados a $4^{\circ} \mathrm{C}$, quebrados e determinada a fertilidade pela morfologia do disco germinativo (KOSIN, 1945). De 06 ovos por unidade experimental, identificados como férteis, o albúmen foi retirado e foram obtidos fragmentos de $15 \times 15 \mathrm{~mm}$ da membrana perivitelínica sobre o disco germinativo, os quais foram lavados em solução de $\mathrm{NaCl} 1 \%$ para remoção do vitelo, esticados em lâmina histológica, tratados com marcador de DNA DAPI (4',6-diamidino-2-fenilindole, dihidroclorido), diluído $1 \mu \mathrm{g} / \mathrm{mL}$, para identificação do espermatozóide (WISHART, 1987). As amostras foram analisadas em microscópio de fluorescência e analisada uma área total de $3,75 \mathrm{~mm}^{2}$, sob objetiva de $20 \mathrm{x}$ por ovo. Os núcleos de espermatozóides foram contados e representados em número de sptz/$/ \mathrm{mm}^{2}$.

\section{Morfologia dos órgãos genitais}

Dos tratamentos com machos e fềmeas de mesma idade (100,180, 260 e 410 dias), 16 codornas (8 machos e 8 fêmea) foram escolhidos aleatoriamente para descrever a morfometria dos órgãos genitais. As aves foram pesadas, dessensibilizadas por eletrochoque e sacrificadas por deslocamento cervical. Os órgãos genitais foram isolados, pesados e medidos com paquímetro digital. Dos testículos foram obtidos a largura e o comprimento e dos segmentos do oviduto o comprimento do infundíbulo, do magno, do istmo, do útero e da vagina.

Para a histomorfometria, de 4 aves/idade/sexo, fragmentos dos diferentes segmentos do oviduto e dos testículos foram fixados em formaldeído $10 \%$, PBS $0,1 \mathrm{M}$, por imersão. As amostras foram processadas na rotina histológica e os cortes histológicos de 7 
$\mu \mathrm{m}$ foram corados em Hematoxilina e Eosina e analisados em microscópio de luz. Foram obtidas imagens digitais no software Motic Images Plus $2.0^{\circledR}$ e as mesmas foram analisadas para determinar as seguintes variáveis morfométricas: testículos: diâmetro dos túbulos seminíferos, altura do epitélio germinativo; e oviduto: altura das pregas do infundíbulo, do magno, do istmo, do útero e da vagina. Para cada variável analisada, foram obtidas 50 mensurações em diferentes cortes, para cada ave.

\section{Análise estatística}

As análises estatísticas das médias estimadas para qualidade de ovo, desempenho produtivo, morfologia e interação espermatozóide-ovo foram realizadas utilizando-se o SAS (2009). Os efeitos foram verificados por meio de regressão, em $5 \%$ de significância, seguindo-se os modelos a seguir:

$Y=\mu+F E+M A+F E \cdot M A+e_{i}$ (geral), onde:

$Y$ : Resposta de interesse para o animal $i$ no Tratamento $j$;

FE: Fêmeas (Fator com 4 idades: 83, 165, 250 e 398 dias);

$M A$ : Machos (Fator com 4 idades);

FE.MA: Interação;

$e$ : erro $\sim \operatorname{Beta}(\mathrm{a}, \mathrm{b})$

Foram verificadas a homogeneidade de variância por meio do teste de Bartlett e a normalidade nos resíduos por meio do teste Cramer-von Mises. Quando tais suposições não foram satisfeitas, o Log foi utilizado para minimizar a variância nos dados, o procedimento utilizado foi o PROC GLM do software SAS. Para os dados de espermatozóides presos na camada perivitelínica, foi feito conversão logarítmica. Em situações em que a variável resposta é um valor restrito no intervalo $(0,1)$, a distribuição Beta é sugerida como um modelo mais parcimonioso do que simplesmente assumir normalidade, como feito usualmente em determinadas áreas. Esse método foi utilizado nas análises de embriodiagnóstico.

O procedimento de estimação dos parâmetros de regressão Beta foi desenvolvido por meio do pacote betareg do R (CRIBARI-NETO; ZEILEIS, 2010). O Quadrado Médio do Resíduo (MSE) foi utilizado para a realização das comparações múltiplas entre médias dos $k$-níveis de $x$, por meio dos Intervalos de Confiança dos contrastes $\left(\Delta=\mu_{i}-\mu_{j} ; i \neq j\right)$ do teste Tukey (MONTGOMERY, 1991), dado por ( $\Delta$ \pm d.m.s.):

$$
\frac{q_{\alpha(k, N-k)}}{\sqrt{2}} \sqrt{M S E\left(\frac{1}{n_{i}}+\frac{1}{n_{j}}\right)} \text {, q: }
$$

amplitude total studentizada.

Considerou-se como diferentes, ao nível de 5\% de significância, os níveis de tratamentos cujos Intervalos de Confiança para as diferenças médias (contraste $\Delta$ ) não contemplaram o valor zero.

\section{Resultados}

A influência da idade dos reprodutores de codornas depostura, machos e fêmeas foi investigada. Avaliaram-se os parâmetros reprodutivos de fertilidade e de incubação, a morfometria dos órgãos genitais e a qualidade de ovos das matrizes com diferentes idades. Adicionalmente, as filhas resultantes da incubação foram acompanhadas e analisados o desempenho e a qualidade de ovos.

Os dados de qualidade de ovos das matrizes de codornas de postura estão representados na Tabela 1. Não houve efeito $(P>0,05)$ da idade das fêmeas para peso do ovo, unidade Haugh, percentagem da gema e casca e para espessura da casca. Já a análise da probabilidade de postura através de regressão beta apresentou comportamento linear $(\mathrm{P}<0,05)$, reduzindo em função da idade das fêmeas (Fig. 1). 
Tabela 1. Valores médios da qualidade dos ovos de codornas de postura com diferentes idades.

\begin{tabular}{ccccccc}
\hline Idade & $\begin{array}{c}\text { Postura } \\
(\%)\end{array}$ & $\begin{array}{c}\text { Peso ovo } \\
(\mathbf{g})\end{array}$ & $\begin{array}{c}\text { Unidade } \\
\text { Haugh }\end{array}$ & $\begin{array}{c}\text { Gema } \\
\mathbf{( \% )}\end{array}$ & $\begin{array}{c}\text { Casca } \\
(\mathbf{\%})\end{array}$ & $\begin{array}{c}\text { Espessura } \\
\text { da casca }(\mathbf{m m})\end{array}$ \\
\hline 80 & 90,84 & 10,75 & 93,11 & 28,85 & 7,72 & 0,219 \\
160 & 90,52 & 11,22 & 91,45 & 29,94 & 7,91 & 0,221 \\
240 & 85,00 & 11,07 & 90,94 & 29,91 & 7,86 & 0,216 \\
390 & 74,56 & 11,11 & 91,28 & 30,15 & 7,58 & 0,213 \\
\hline Média & 85,23 & 11,04 & 91,69 & 29,71 & 7,77 & 0,217 \\
\hline CV (\%) & 11,01 & 4,44 & 1,95 & 3,59 & 3,85 & 3,73 \\
Interação & ns & $\mathrm{ns}$ & $\mathrm{ns}$ & $\mathrm{ns}$ & $\mathrm{ns}$ & $\mathrm{ns}$ \\
Efeito & Linear $^{*}$ & $\mathrm{~ns}$ & $\mathrm{~ns}$ & $\mathrm{~ns}$ & $\mathrm{~ns}$ & $\mathrm{~ns}$ \\
\hline
\end{tabular}

$\mathrm{CV}=$ coeficiente de variação; ns $=$ não significativo. ${ }^{*} \mathrm{P}<0,05$.

Fonte: Elaboração dos autores.

Figura 1. Probabilidade de postura em fêmeas de codorna em função da idade da matriz. Postura $=\exp (2,6714-0,004049 \mathrm{x}) /(1+\exp (2,6714-0,004049 \mathrm{x}))$.

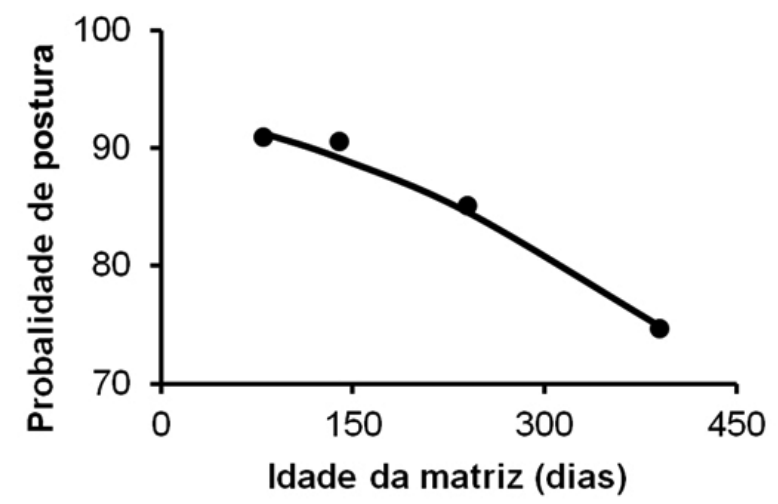

Fonte: Elaboração dos autores.

Com relação à análise dos dados de embriodiagnóstico, as variáveis analisadas não apresentaram distribuição normal, com exceção do peso do pintainho. As médias foram convertidas em logaritmos para análise estatística. Verificou-se que não houve efeito $(\mathrm{P}>0,05)$ de interação entre idade dos machos e das fêmeas, nem para os fatores estudados isoladamente. Para caráter descritivo, as médias de embriodiagnóstico estão apresentadas na Tabela 2. O peso médio dos pintainhos foi analisado separadamente sem efeito $(\mathrm{P}>0,05)$ da idade dos reprodutores.

$\mathrm{Na}$ análise das camadas perivitelínicas de ovos férteis foram identificados os espermatozóides após marcação por DAPI. Esse reagente associa-se ao DNA tornando-o fluorescente, e, desta forma, o espermatozóide torna-se visível como uma estrutura alongada e vermiforme (Fig. 2). Também foram visualizadas células embrionárias isoladas ou em aglomerações e várias concreções minerais (Fig. 2). Em médias as fêmeas tiveram 7,71 $\pm 2,50 ; 10,00$ $\pm 5,12 ; 9,71 \pm 4,38$ e $14,20 \pm 4,27 \mathrm{sptz} / \mathrm{mm}^{2}$ para as idades 80,160, 240 e 390 dias, respectivamente. Para os dados médios convertidos em logaritmos e analisados por regressão, não houve efeito da idade do macho e houve efeito quadrático $(\mathrm{P}<0,05)$ da idade da fêmea (Tabela 3, Figura 3). As fêmeas mais jovens apresentam maior número de espermatozóides presos na camada perivitelínica, e esse número caiu com o passar da idade, conforme é observado na Figura 3. A queda no número de espermatozóides ocorreu até os 348 dias de idade na fêmea, permanecendo então estável. 
Tabela 2. Valores médios de parâmetros de incubação e do peso dos pintainhos em função da idade das matrizes fêmeas e machos de codornas de postura.

\begin{tabular}{|c|c|c|c|c|c|c|c|c|}
\hline \multirow{2}{*}{ Idade } & \multirow{2}{*}{$\begin{array}{c}\text { Peso } \\
\text { pinto }(\mathrm{g})\end{array}$} & \multirow{2}{*}{$\begin{array}{l}\text { Fertilidade } \\
\text { (\%) }\end{array}$} & \multirow{2}{*}{$\begin{array}{c}\text { Eclodibilidade } \\
(\%)\end{array}$} & \multicolumn{5}{|c|}{ Mortalidade (\%) } \\
\hline & & & & Total & Precoce & Intermed. & Tardia & Casca \\
\hline \multicolumn{9}{|l|}{ Fêmeas } \\
\hline 80 & 7,64 & 93,49 & 91,89 & 8,2 & 1,74 & 1,63 & 2,36 & 2,38 \\
\hline 160 & 7,69 & 92,23 & 91,31 & 8,69 & 1,25 & 1,58 & 2,4 & 3,46 \\
\hline 240 & 7,67 & 89,55 & 86,45 & 13,54 & 3,18 & 2,98 & 3,4 & 3,98 \\
\hline 390 & 7,71 & 85,56 & 77,81 & 22,19 & 4,58 & 4,96 & 5,79 & 6,86 \\
\hline \multicolumn{9}{|l|}{ Machos } \\
\hline 80 & 7,67 & 91,44 & 87,82 & 12,18 & 1,91 & 2,03 & 4,06 & 4,17 \\
\hline 160 & 7,69 & 92,07 & 85,06 & 14,94 & 3,27 & 4,65 & 4,11 & 2,91 \\
\hline 240 & 7,68 & 87,50 & 82,99 & 17,01 & 3,79 & 3,67 & 4,35 & 5,20 \\
\hline 390 & 7,69 & 89,83 & 91,59 & 8,41 & 1,78 & 0,80 & 1,43 & 4,40 \\
\hline Média & 7,68 & 90,21 & 86,87 & 13,14 & 2,69 & 2,79 & 3,49 & 4,17 \\
\hline CV $(\%)$ & 4,74 & 10,58 & 15,34 & 101,51 & - & - & - & - \\
\hline Interação & ns & ns & $\mathrm{ns}$ & ns & $\mathrm{ns}$ & $\mathrm{ns}$ & ns & $\mathrm{ns}$ \\
\hline Efeito & $\mathrm{ns}$ & $\mathrm{ns}$ & $\mathrm{ns}$ & ns & $\mathrm{ns}$ & $\mathrm{ns}$ & ns & $\mathrm{ns}$ \\
\hline
\end{tabular}

$\mathrm{CV}=$ coeficiente de variação; ns = não significativo.

Fonte: Elaboração dos autores.

Figura 2. A) Superfície da gema do ovo evidenciando o disco germinativo de um ovo infértil (inf) e de um ovo fértil (fer). B-D) membranas vitelínicas de ovos de codornas de postura preparadas com DAPI em que vê-se as concreções minerais descritas como "sperm body" (sb), células embrionárias caracterizadas pelo núcleo arredondado (ger) e espermatozóides (sptz) caracterizados pelo formato irregular e encurvado de seu núcleo. Barra $50 \mu \mathrm{m}$.

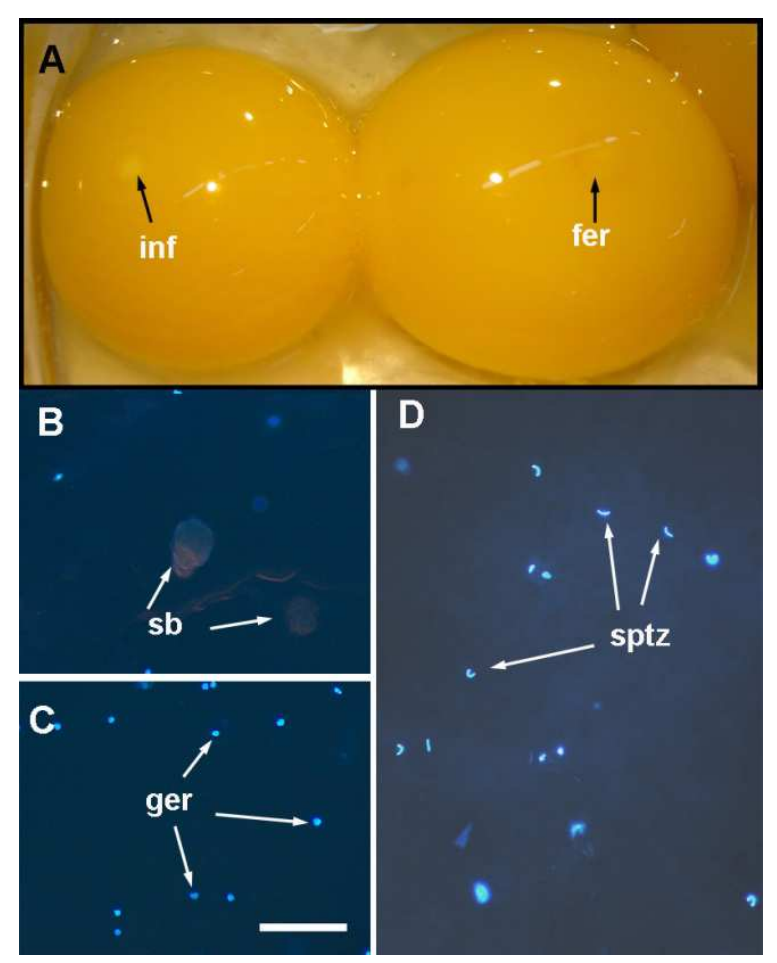

Fonte: Elaboração dos autores. 
Figura 3. Número de espermatozóide/mm2 por ovo fértil em matrizes de codornas de corte em função da idade.

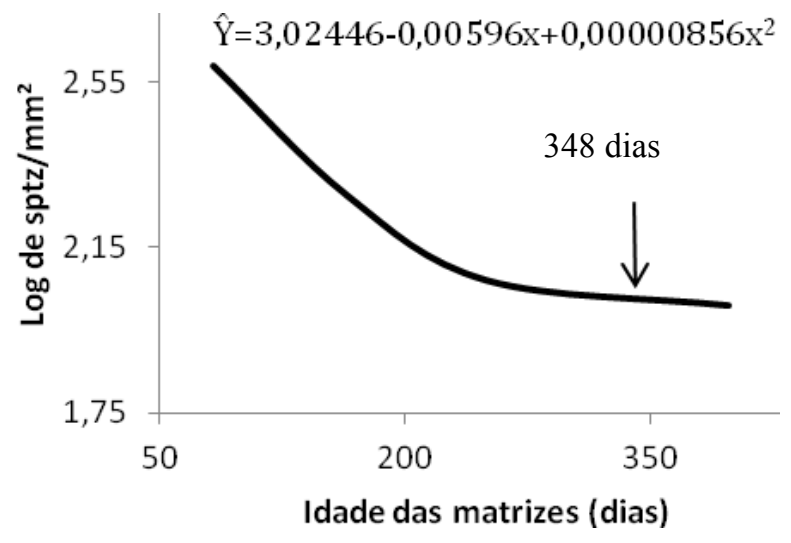

Fonte: Elaboração dos autores.

Tabela 3. Significância dos Parâmetros (p-valor) no modelo pela análise de variância para Log de número de espermatozóides $/ \mathrm{mm}^{2}$

\begin{tabular}{lcccc}
\hline $\begin{array}{l}\text { Variável } \\
\text { Dependente }\end{array}$ & FE & Variáveis Regressoras & CV\% \\
\hline SPTZ & $<0,0001$ & MA & FE.MA & \\
\hline
\end{tabular}

Fonte: Elaboração dos autores.

O desempenho e a qualidade dos ovos das fêmeas de codornas de postura filhas dos mesmos tratamentos foram analisados em função da idade dos reprodutores de postura machos e fêmeas. Não houve efeito $(\mathrm{P}>0,05)$ para as médias das variáveis analisadas: porcentagem de casca, peso do ovo, espessura, gravidade e unidade Haugh, consumo de ração e conversão alimentar (Tabela 4).

Os órgãos genitais foram avaliados morfologicamente nas fêmeas e machos reprodutores nas diferentes idades utilizados no experimento e as médias obtidas estão representadas na Tabela 5 .
As variáveis analisadas não tiveram efeito da idade dos reprodutores $(\mathrm{P}>0,05)$. $\mathrm{O}$ peso do ovário, do oviduto e dos testículos não foi influenciado pela idade dos reprodutores de forma significativa. As médias de comprimento macroscópico, altura e largura das pregas da mucosa dos diferentes segmentos do oviduto (infundíbulo, magno, istmo, útero e vagina), bem como a altura do epitélio germinativo e o diâmetro dos túbulos seminíferos não apresentaram diferenças significativas $(\mathrm{P}>0,05)$ em função da idade dos reprodutores. 
Tabela 4. Qualidade dos ovos e desempenho de codornas japonesas resultantes de cruzamentos de matrizes com idades diferentes.

\begin{tabular}{|c|c|c|c|c|c|c|c|c|}
\hline \multirow{2}{*}{$\begin{array}{l}\text { Idade } \\
\text { (dias) }\end{array}$} & \multirow{2}{*}{$\begin{array}{c}\text { Peso } \\
\text { ovo (g) }\end{array}$} & \multirow{2}{*}{$\begin{array}{c}\text { Casca } \\
(\%)\end{array}$} & \multirow{2}{*}{$\begin{array}{c}\text { Casca } \\
\text { Espessura (mm) }\end{array}$} & \multirow{2}{*}{$\begin{array}{l}\text { Gravidade } \\
\text { específica }\end{array}$} & \multirow{2}{*}{$\begin{array}{c}\text { Unidade } \\
\text { Haugh }\end{array}$} & \multirow{2}{*}{$\begin{array}{l}\text { Consumo } \\
\text { g/ave/dia }\end{array}$} & \multicolumn{2}{|c|}{ Conversão } \\
\hline & & & & & & & $\mathrm{kg} / \mathrm{kg}$ & kg/dúzia \\
\hline \multicolumn{9}{|l|}{ Fêmea } \\
\hline 390 & 10,77 & 7,59 & 0,238 & 1,069 & 92,25 & 24,02 & 2,93 & 0,380 \\
\hline 240 & 10,78 & 7,75 & 0,237 & 1,084 & 91,21 & 23,26 & 3,10 & 0,399 \\
\hline 160 & 10,80 & 7,59 & 0,235 & 1,071 & 90,64 & 23,44 & 2,93 & 0,376 \\
\hline 80 & 10,76 & 7,62 & 0,230 & 1,072 & 90,93 & 23,15 & 3,01 & 0,391 \\
\hline \multicolumn{9}{|l|}{ Macho } \\
\hline 390 & 10,99 & 7,54 & 0,236 & 1,071 & 91,40 & 23,34 & 2,73 & 0,367 \\
\hline 240 & 10,78 & 7,66 & 0,231 & 1,070 & 91,11 & 23,34 & 3,23 & 0,419 \\
\hline 160 & 10,71 & 7,66 & 0,235 & 1,081 & 91,50 & 23,61 & 2,94 & 0,379 \\
\hline 80 & 10,62 & 7,70 & 0,238 & 1,074 & 91,02 & 23,58 & 2,99 & 0,381 \\
\hline Média & 10,77 & 7,64 & 0,235 & 1,074 & 91,26 & 23,47 & 2,99 & 0,387 \\
\hline $\mathrm{CV} \%$ & 4,84 & 4,06 & 3,36 & 2,27 & 1,57 & 6,33 & 15,19 & 14,25 \\
\hline Interação & ns & ns & ns & ns & ns & ns & ns & ns \\
\hline Efeito & ns & ns & ns & ns & ns & ns & ns & ns \\
\hline
\end{tabular}

$\mathrm{CV}=$ coeficiente de variação; $\mathrm{ns}=$ não significativo.

Fonte: Elaboração dos autores.

$\mathrm{Na}$ análise microscópica foram avaliadas a altura e largura das pregas da mucosa nos segmentos do oviduto. No infundíbulo as pregas da mucosa são ramificadas e delicadas $(185,34$ x 73,00 $\mu \mathrm{m}$ de altura e largura, respectivamente) (Figura 4A). No magno as pregas assumem considerável altura e largura $(1.684,09 \times 711,23 \mu \mathrm{m})$, e a submucosa encontra-se repleta por glândulas com citoplasma eosinófilo (Figura 4B). No istmo estas pregas reduzem de tamanho (959,99 x 343,42 $\mu \mathrm{m})$, apresentam menor quantidade de glândulas e na mucosa do útero as pregas voltam a aumentarem (1.256,95 x 261,01 $\mu \mathrm{m})$, com pregas ramificadas, com presença de glândulas na submucosa e com a mucosa macroscopicamente escura (Figura 4CD). A mucosa da vagina apresentou pregas baixas ricas em glândulas tubulares armazenadoras de espermatozóides (Figura 4E-F).
Nos machos, o testículo direito se mostrou mais longo e mais estreito (Figura 4G), em comparação com os valores encontrados para o testículo esquerdo (Tab. 5). Essa diferença morfométrica refletiu a posição que os mesmos ocupam na cavidade celomática, sendo o testículo direito ligeiramente mais cranial que o esquerdo. Microscopicamente, os testículos de codornas apresentaram túbulos seminíferos desenvolvidos e ativos, com espermatozóides na luz tubular em todas as idades analisadas (Figura 4H-I). Em média, os túbulos seminíferos dos machos entre 100 e 410 dias de vida apresentaram diâmetro de 231,54 $\mu \mathrm{m}$ e altura do epitélio germinativo de $69,19 \mu \mathrm{m}$. 
Tabela 5. Valores médios morfométricos macroscópicos de órgãos genitais femininos e masculinos e peso vivo de codornas japonesas em diferentes idades.

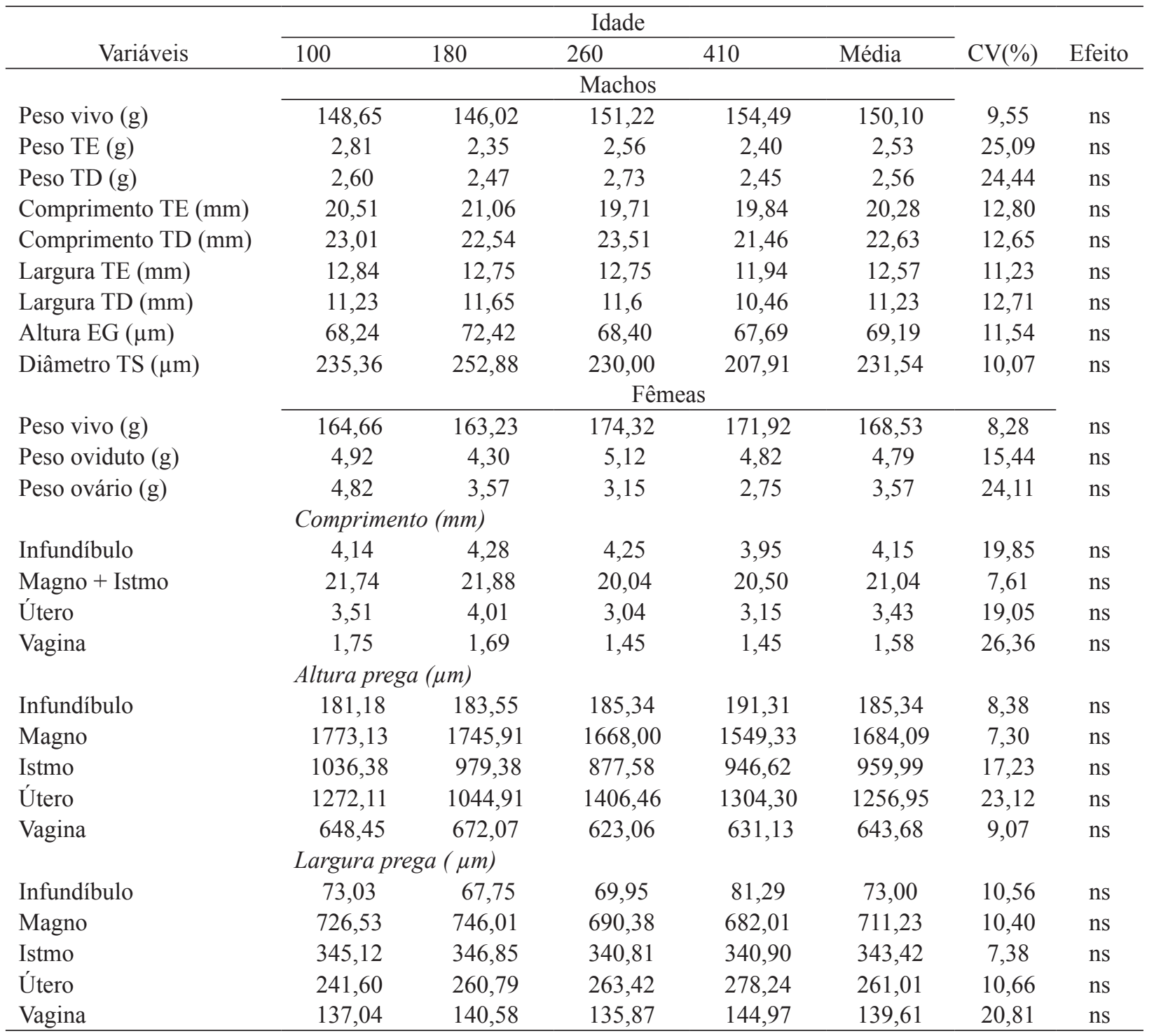

TE: testículo esquerdo, TD: testículo direito; EP: epitélio germinativo, TS: túbulo seminífero, CV: coeficiente de variação; ns: não significativo.

Fonte: Elaboração dos autores. 
Figura 4. Detalhes microscópicos do oviduto e macro e microscópicos dos testículos de reprodutores de codornas de postura. Segmentos do oviduto: infundíbulo (A), magno (B), istmo (C) e útero (D) e da vagina (E-F) de codorna de postura. A-D) Notar as diferenças na forma e tamanho das pregas (pr) da mucosa em cada segmento. F) Detalhes das glândulas armazenadoras de espermatozóides (sptz) que estão localizadas na transição entre vagina e útero. G) Vista ventral da cavidade celomática exposta evidenciando os testículos direito (td) e esquerdo (te) in situ. Observar a diferença em forma e tamanho dos mesmos. H-I) Fotomicrografias do testículo evidenciando a forma e desenvolvimento dos túbulos seminíferos (tub), compostos pelo epitélio germinativo (ger) com espermatozóides na luz tubular. Hematoxilina Eosina. Barras: A, H) $100 \mu \mathrm{m}$; B-D) $200 \mu \mathrm{m}$, I) $100 \mu \mathrm{m}$, F) $10 \mu \mathrm{m}$.

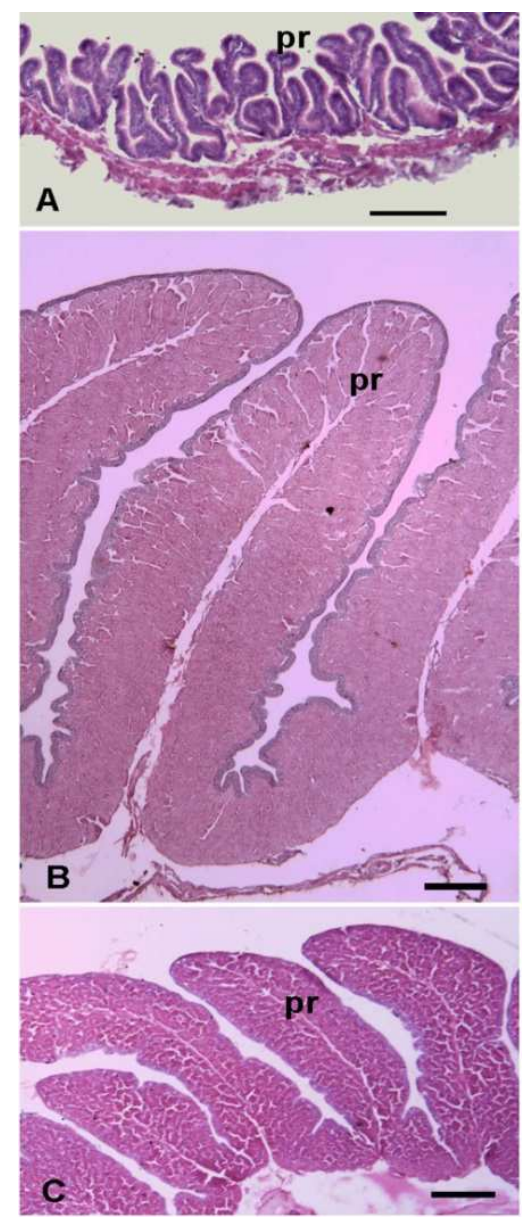

Fonte: Elaboração dos autores.
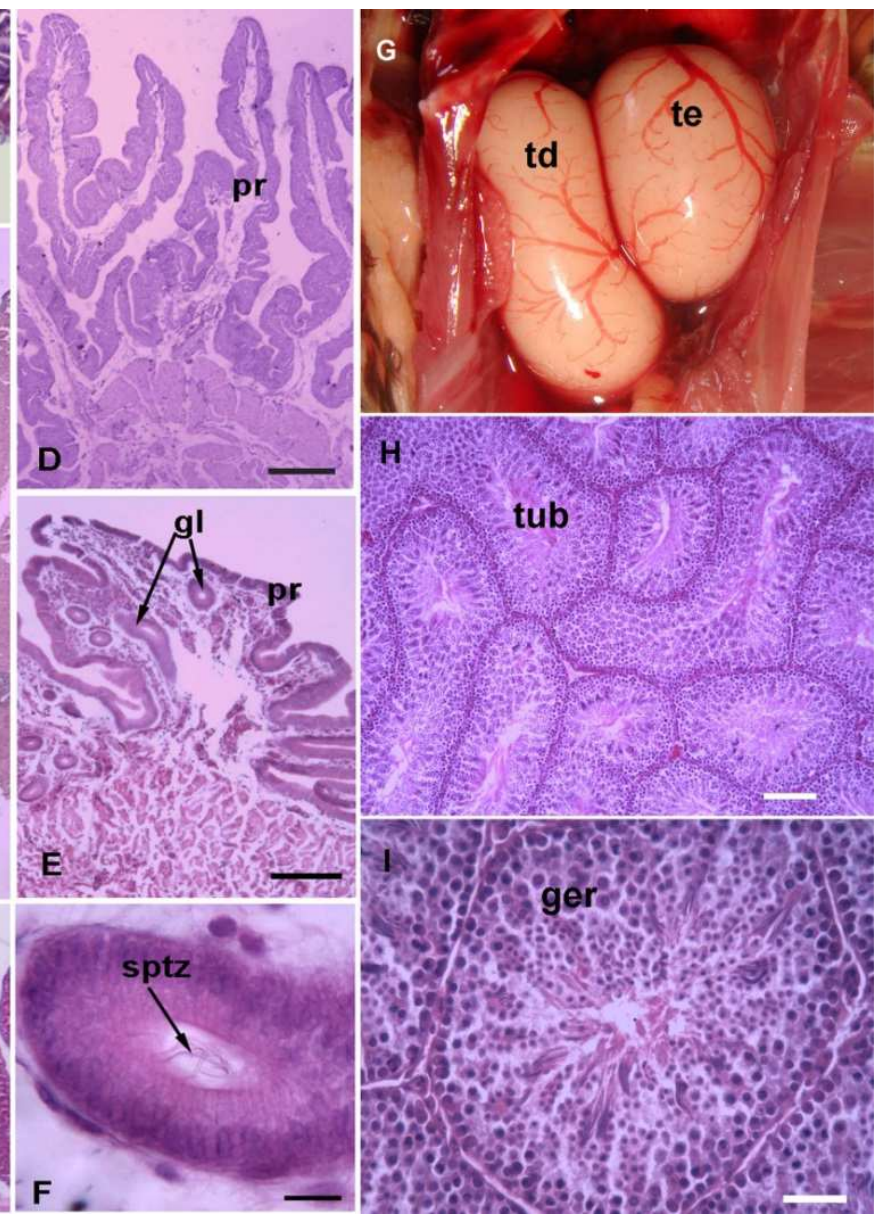

\section{Discussão}

Neste trabalho foi avaliada a influencia da idade em reprodutores de codornas de postura. As variáveis analisadas sinalizam que a idade da fêmea é o principal fator na reprodução de codornas de postura. A produção de ovos e a qualidade dos ovos foram avaliados para identificar se as matrizes estavam com as características descritas para cada idade testada para que os resultados reprodutivos observados pudessem ser realmente em função da diferença da idade e não resultado de outros fatores. Os índices de produção de ovos e as variáveis de qualidade dos ovos estavam dentro do descrito para codornas de postura criadas no Brasil. Normalmente os experimentos de produção de ovos são realizados com codornas em idade de pico de postura até 140 dias (20 semanas). Nas codornas estudadas não foram observados efeitos para as variáveis de qualidade de ovos, sendo que a postura decresceu à medida que as aves foram ficando mais velhas. As 
aves com 390 dias apresentaram 15\% a menos de postura. Não foi observado efeito para a regressão sobre peso do ovo e espessura de casca.

Nas codornas analisadas não foi observado efeito da idade no peso do ovo e, conseqüentemente, nem no peso dos pintainhos. A redução da espessura da casca do ovo e o aumento no peso e na proporção da gema são observados em poedeiras comerciais e em matrizes de frango de corte (BURLEY; VADEHRA, 1989). Com o envelhecimento das matrizes avícolas, são produzidos folículos maiores, o que resulta na produção de ovos maiores e, também, no aumento da relação entre o peso da gema e peso do ovo (VIEIRA et al., 2001), e, ao mesmo tempo, os ovos sofrem diminuição de espessura da casca e do número e diâmetro dos poros (CARDOSO et al., 2002). Desta forma aves mais jovens apresentam valores superiores para percentagem de casca em relação às aves mais velhas (SILVERSIDES; ESCOTT, 2001). Hamilton (1982), estudando poedeiras, comenta que as galinhas tendem a produzir ovos com casca de qualidade inferior à medida que envelhecem, isso pode ser explicado devido ao fato de que os ovos são de maior tamanho e apresentam menor proporção da casca. Fletcher et al. (1983) mostraram valores de unidades Haugh para ovos frescos, diminuindo com o aumento da idade das poedeiras, assim como menor relação gema albúmen em galinhas mais velhas e redução na quantidade de sólidos (AHN; KING; SHU, 1997).

Apenas alguns autores descrevem diferenças para estas variáveis em codornas mais velhas, como é o caso de Nowaczewski et al. (2010), os quais descreveram em aves de 217 dias, aumento de tamanho do ovo com a idade em codornas japonesas. A variação de valores na qualidade de casca de ovos de codornas de postura em função de idade das fêmeas é citada em experimentos que estudaram diferentes níveis de cálcio e fósforo na dieta (COSTA; BRANDÃO; SILVA, 2009).

Conforme visto em matrizes de frango de corte, a produção de ovos também apresentou queda com o aumento da idade em codornas $(\mathrm{P}<0,05)$. Apesar de as fêmeas com maior idade deste experimento já serem consideradas velhas para produção de ovos férteis, as aves com 55 semanas ainda apresentam $75 \%$ de postura. Matrizes pesadas apresentam pico de postura seguido de declínio gradual na produção, devido a uma redução na sequência, apresentando maior proporção de dias sem oviposição (LEESON; SUMMERS, 2000).

Com relação aos dados de incubação obtidos, o peso dos pintainhos não foi diferente nas fêmeas com 390 dias em relação às demais idades. O que se evidenciou foi que a idade das mães e dos pais não interferiu sobre a produção e qualidade de ovos das filhas. Como não houve efeito no peso dos ovos e no peso dos pintainhos de 1 dia, acreditase que o mesmo aporte nutricional foi fornecido aos pintainhos durante a incubação em ovos provenientes de codornas jovens ( 80 dias), adultas (160 e 240) e velhas (390 dias). Em matrizes de frango de corte, os pintos originados de matrizes mais jovens apresentaram peso significativamente menor à eclosão $(44,1 \mathrm{~g})$ do que os provenientes de lote mais velho $(49,1 \mathrm{~g})$, isso é explicado pelo fato de que galinhas apresentam aumento no peso do ovo no decorrer da vida reprodutiva, aumentando, consequentemente, o peso dos pintainhos (REIS; GAMA; SOARES, 1997). Porém, Corrêa (2010) encontrou em codornas de corte que filhas oriundas de fêmeas mais velhas apresentaram maior peso corporal aos 42 dias $(298,64 \mathrm{~g}$ para filhas oriundas de fêmeas com 280 dias e 277,40 para filhas oriundas de matrizes com 70 dias).

Outra variável analisada foi a eclodibilidade. Em codornas, a queda na eclodibilidade não foi observada, mantendo a taxa de eclosão sem diferenças $(\mathrm{P}>0,05)$ por todo o período estudado. A mortalidade embrionária observada no presente experimento não apresentou diferenças entre os tratamentos ou efeito da idade das matrizes, tanto machos quanto fêmeas $(\mathrm{P}>0,05)$, com média de $13,13 \%$. Valores aproximados também foram encontrados por Pedroso et al. (2006) $(23,41 \%)$, 
estudando codornas japonesas com 133 dias de idade.

Com relação a fertilidade, as médias nas idades mais velhas forma inferiores, mas sem efeito significativo na regressão, desta forma considerase que para as idades analisadas (80 a 390 dias de idade) as codornas apresentaram fertilidade média de 90,2\%. Nesse experimento, as fêmeas de cada idade foram selecionadas para postura antes da formação dos grupos reprodutores, de forma indireta, pode-se ter selecionado as melhores aves e os resultados de fertilidade ter refletido esse efeito, apesar da redução significativa na postura.

A idade das fêmeas tem sido descrita como o principal fator interferindo na fertilidade de codornas japonesas. Santos et al. (2011) descreveram que a fertilidade decresce em função da idade da fêmea. As codornas teriam a capacidade de manter a fertilidade e o numero de espermatozoides no oviduto até 335 dias e após esse período ambos reduzem em função da idade da fêmea. Em outro estudo, Santos et al. (2011) descreveram uma fertilidade superior para codornas de 120 dias de idade, com média de 98,15\%. Já em grupos de matrizes mais velhas, com aproximadamente 310 dias de idade, Hassan et al. (2003) encontraram valores de fertilidade de $72,1 \%$, valores inferiores aos encontrados no presente experimento.

$\mathrm{Na}$ análise da camada perivitelínica de ovos férteis foram observadas concreções minerais. Essas são descritas como "sperm body" por Sultana, Mao e Yoshizaki (2004). Estes autores descrevem que flagelos dos espermatozóides foram observados juntos a estes corpos e sugeriram que estes parecem auxiliar na fertilização por fornecerem cálcio. Rabbani et al. (2007) também observaram que durante a fertilização, o corpo associado ao espermatozóide fica preso na parte posterior de seus flagelos. A presença do corpo associado ao espermatozóide também foi confirmada como necessária para que espermatozóides férteis façam buracos na camada perivitelínica e ocorra o sucesso na fertilização. Durante a anális das amostras em várias ocasiões os espermatozóides foram observados sobre essas concreções minerais. Porém estudos especificos precisam ser desenvolvidos para compravar essa hipótese.

As possíveis causas para o declínio na fertilidade de galinhas velhas reportadas por Bramwell, Marks e Howarth (1995) incluem problemas na capacidade de estocar espermatozóides em seu trato reprodutor ou um declínio na habilidade de transportar esses espermatozóides para o local de fertilização. Os autores sugerem três possibilidades para esse efeito: 1) os espermatozóides são liberados dos túbulos de estocagem com maior rapidez ou em maior número em galinhas velhas, 2) a estocagem de espermatozóides não garante a viabilidade destes por muito tempo, como ocorre em galinhas jovens, e 3) o número de receptores para espermatozóides na superfície do oócito diminuíram com o avançar da idade em aves. Estas são, provavelmente, as mesmas razões para o declínio no número de espermatozóides presos à camada perivitelínica de codornas de postura, observado neste experimento.

A idade dos machos de codornas não exerceu influência no parâmetro fertilidade. Em galos existe um declínio normal da fertilidade a partir de 40 semanas de idade, como conseqüencia da redução da atividade sexual e menor produção de espermatozóides (HOCKING, 1990). Já em outros trabalhos, comparando galos com 35 e 68 semanas de idade, Rocha Júnior e Baião (2001) concluíram que não houve diferença nas características espermáticas entre as idades. Nos galos, a redução na fertilidade está associada a redução no número de espermatozóides no ejaculado e na redução do volume de sêmen produzido (LAKE, 1989), apresentam também libido diminuída e menor número de cópulas férteis (WILSON et al., 1979). Nas codornas analisadas não foram avaliados os parâmetros seminais dos machos, porém, o numero de espermatozóides fornece uma visão indireta da quantidade de espermatozóides que as fêmeas receberam naquele período. 
Com relação ao desempenho produtivo da progênie, as citações na literatura são referentes a frangos de corte e não a aves de postura, mas os principais efeitos estão associados ao aumento no tamanho do ovo em galinhas em função da idade. Maiorka (2002) descreve que pintainhos originados de matrizes velhas apresentam trato digestório mais desenvolvido no momento da eclosão, o que pode melhorar o aproveitamento e adaptação a alimentação exógena como também pode apresentar um melhor desempenho destes animais (HUDSON et al., 2004). Também em matrizes foi observado que pintainhos originados de matrizes mais velhas apresentaram maior consumo de ração por serem mais pesados que aqueles oriundos de fêmeas mais jovens (ALMEIDA et al., 2006). Proudfoot, Hulan e McCrae (1982), trabalhando com matrizes, também verificaram melhor conversão alimentar para pintainhos provenientes de ovos maiores. Em codornas, o desempenho das filhas se manteve o mesmo quando comparadas às diferentes idades dos reprodutores. Isso pode ser explicado pelo fato de codornas não apresentarem aumento no peso do ovo, consequentemente, não houve aumento no peso do pintainho e esses efeitos observados em matrizes não se refletiram nas codornas de postura. Corrêa (2010) estudando codornas de corte observou maior consumo de ração em codornas oriundas de matrizes mais velhas $(22,46 \mathrm{~g} /$ dia para aves com 280 dias e $21,27 \mathrm{~g} /$ dia para aves com 70 dias).

Com relação a analise morfológica dos órgãos genitais, os resultados encontrados foram semelhantes aos descritos por Artoni etal. (2001) para peso de ovário (4,85 g), oviduto (7 g), comprimento do infundíbulo $(4,15 \mathrm{~cm})$, comprimento do magnoistmo $(19,37 \mathrm{~cm})$, comprimento do útero $(2,45 \mathrm{~cm})$ e comprimento da vagina $(1,10 \mathrm{~cm})$. A maior porção do oviduto está representada pelo magno + istmo e é descrita em outras aves como na galinha (KING, 1981) e nas patas (DAS; MISHRA; BISWAL, 1965). O magno, responsável pela secreção de albúmen, não sofreu modificação morfológica com o avanço da idade da fêmea, resultado este esperado já que a unidade Haugh, que demonstra a proporção de albúmen no ovo, também não sofreu efeito da idade, sendo estatisticamente semelhante entre aves com 80 e 390 dias de vida, demonstrando que a quantidade de albúmen foi semelhante ao longo da idade das aves. A mucosa do útero foi semelhante ao descrito por Bradley e Grahame (1950), neste segmento ocorre a calcificação da casca do ovo, o que explica em parte a estabilidade dos valores de espessura e \% de casca durante a vida reprodutiva da codorna.

Para os machos, os reprodutores apresentaram características sexuais ativas aos 410 dias de idade, representadas pelos parâmetros testiculares macro e microscópicos. Resultado semelhante também foi observado em codornas japonesas com idade de 60 a 180 dias que apresentam peso testicular médio de 3,005 g (AMOROSO et al., 2008). Já no caso de galos, pode ser considerada uma alteração no peso e no comprimento dos testículos no decorrer da vida reprodutiva, diferindo dos resultados observados em codornas (BULL et al., 2007).

As variações sazonais normalmente descritas em testículos de codornas (AMOROSO et al., 2008), como o diâmetro dos túbulos seminíferos, altura do epitélio germinal e peso testicular não foram observadas pelo fato destas aves terem sido criadas em regime de luz controlada $(17 \mathrm{~h}$ de luz) e, portanto, não apresentaram sazonalidade característica. Esses resultados demonstraram que não houve alterações nas características macro e microscópicas testiculares em função da idade dos machos. Associa-se a estes resultados, o fato de que não houve redução na fertilidade, quando esta foi determinada na incubação dos ovos oriundos dos mesmos grupos reprodutores que os machos analisados, e pode-se supor que nas codornas japonesas reprodutoras a idade dos machos até 410 dias mantém o potencial reprodutivo.

A redução no número de espermatozóides que atingem o oócito no infundíbulo, está associada a idade das fêmeas pela provável redução na 
habilidade de estocar e manter os espermatozóides nas glândulas tubulares da mucosa da vagina, como já mencionado anteriormente. Apesar de não ter sido realizado neste experimento análise seminal, o peso e o comprimento testicular não variaram, assim como os parâmetros microscópicos, sugerindo que nas idades analisadas os machos podem ser considerados sexualmente aptos.

\section{Conclusão}

As reprodutoras de codornas de postura entre 80 e 390 dias de vida conservam as variáveis de qualidade de ovos sem influência na composição e no tamanho do ovo, porém reduzem a taxa de postura. $\mathrm{Na}$ incubação, a eclodibilidade e a fertilidade permanecem sem efeito da idade da fêmea, mas o número de espermatozóides nos ovos férteis reduz em fêmeas mais velhas. Reprodutores de codornas de postura entre 100 e 410 dias de idade conservam a morfometria dos órgãos genitais femininos e masculinos. Nenhuma das variáveis estudadas foi afetada pela idade do macho. Podese indicar o uso de codornas de postura machos e fêmeas como reprodutores até 38 semanas.

\section{Agradecimentos}

Ao $\mathrm{CNPq}$ e a Fundação Araucária, pelo apoio financeiro.

Este trabalho foi desenvolvido com aprovação do Comitê de Ética no Uso de Animais em Experimentação - CEAE/UEM, Protocolo 010/2009.

\section{Referências}

AHN, D. U.; KIN, S. M.; SHU, H. Effect of egg size and strain and age of hens on the solids content of chicken eggs. Poultry Science, Champaign, v. 76, n. 6, p. 914919, 1997.

ALMEIDA, I. C. L.; MENDES, A. A.; QUINTEIRO, R. R.; VULCANO, L. C.; TAKAHASHI, S. E.; GARCIA, R. G.; KOMIYAMA, C. M.; BALOG, A.; PELICIA,
K.; WESCHELER, F. S.; PICCININ, A. Bone mineral density of tibia and femur of broiler breeders: growth, development and production. Brazilian Journal Poultry Science, Campinas, v. 8, n. 2, p. 75-82, 2006.

AMOROSO, L.; BARALDI-ARTONI, S. M.; MORAES, V. M. B.; PERECIN, D.; FRANZO, V. S.; AMOROSO, P. Influência da espermatogênese e dos níveis de testosterona no aspecto reprodutivo de codornas. Revista Brasileira de Zootecnia, Viçosa, v. 37, n. 1, p. 61-66, 2008.

ARTONI, S. M. B.; CARNEIRO, A. P. M.; GIACOMINI, G.; MORAES, V. M. B; ARAÚJO, C. S. S.; ARAÚJO, L. F. Avaliação macroscópica e morfométrica do oviduto de codornas (Coturnix coturnix japonica) quando alimentadas com diferentes níveis de proteína. Revista Brasileira de Ciência Avícola, Campinas, v. 3, n. 3, p. 225-231, 2001.

BAKST, M. R.; HOWARTH, B. The fine structure of the hen's ovum at ovulation. Biology of Reproduction, New York, v. 17, n. 3, p. 370-379, 1977.

BELLAIRS, R.; HARKNESS, M.; HARKNESS, R. D. The vitelline membrane of the hen's egg: a chemical and electron microscopical study. Journal of Ultrastructural Research, San Diego, v. 8, n. 3-4, p. 339-359, 1963.

BRADLEY, O. C.; GRAHAME, T. The structure of the fowl. Edimburg and London: Oliver and Boyd, 1950. $128 \mathrm{p}$.

BRAMWELL, R. K.; MARKS, H. L.; HOWART, H. Quantitative determination of spermatozoa penetration of the perivitelline layer of the hen's ovum as assessed on oviposited eggs. Poultry Science, Champaign, v. 74, n. 11, p. 1875-1883, 1995.

BRAMWELL, R. K.; MCDANIEL, C. D. Influence of spermatozoa numbers and insemination frequency on fertility in dwarf broiler breeder hens. Poultry Science, Champaign, v. 65, n. 12, p. 2330-2334, 1986.

BRILLARD, J. P. Sperm storage and transport following natural mating and artificial insemination. Poultry Science, Champaign, v. 77, n. 5, p. 923-928, 1993.

BULL, M. L.; MARTINS, M. R.; CESÁRIO, M. D.; PADOVANI, C. R.; MENDES, A. A. Anatomical study on Domestic fowl (Gallus domesticus) reproductive system. International Journal of Morphology, Temuco, v. 24, n. 4, p. 709-716, 2007.

BURLEY, R. W.; VADEHRA, D. V. The avian egg: chemistry and biology. New York: John Wiley and Sons, 1989. p. 68-71. 
CARDOSO, A. L. S. P.; TESSARI, E. N. C.; CASTRO, A. G. M.; ZANATTA, G.F. Avaliação da susceptibilidade a antimicrobianos de cepas de Escherichia coli de origem aviária. Arquivo Instituto Biológico, São Paulo, v. 69, n. 2, p. 1-5, 2002.

CLULOW, J.; JONES, R. C. Production, transport, maturation, storage and survival of spermatozoa in the male Japanese quail, Coturnix coturnix. Journal of Reproduction and Fertility, Cambridge, v. 64, n. 2, p. 259-266, 1982.

CORRÊA, A. B. Desempenho e características de carcaça de codornas de corte em função da idade da matriz, peso do ovo e nível nutricional. 2010. Tese (Doutorado em Zootecnia) - Universidade Federal de Minas Gerais, Belo Horizonte.

COSTA, F. G. P.; BRANDÃO, P. A.; SILVA, J. H. V. Exigências de cálcio para codornas japonesas fêmeas de um a 35 dias de idade. Acta Scientiarum Animal Sciences, Maringá, v. 31, n. 1, p. 7-12, 2009.

CRIBARI-NETO, F.; ZEILEIS, A. Beta regression in R. Journal of Statistical Software, Los Angeles, v. 34, n. 2, p. 1-24, 2010.

DAS, L. N.; MISHRA, D. B.; BISWAL, G. Comparative anatomy of the domestic duck (Anas boscas). Indian Veterinary Journal, Madras, v. 42, p. 320-326, 1965.

FASENKO, G. M.; ROBINSON, F. E.; HARDIN, R. $\mathrm{T}$. Variability in preincubation embryonic development in domestic fowl. 2. Effects of duration of egg storage period. Poultry Science, Champaign, v. 71, n. 12, p. 2129-2132, 1992.

FLETCHER, D. L.; BRITTON, W. M.; PESTI, G. M.; RAHN, A. P. The relationship of layer flock age and egg weight on egg component yields and solids content. Poultry Science, Champaign, v. 62, n. 9, p. 1800-1805, 1983.

HAMILTON, R. M. G. Methods and factors that affect the measurement of egg shell. Poultry Science, Champaign, v. 61, n. 10, p. 2022- 2039, 1982.

HASSAN, S. M.; MADY, M. E.; CARTWRIGHT, A. L.; SABRI, H. M.; MOBARAK, M. S. Effect of feeding time on the reproductive performance of Japanese Quail (Coturnix coturnix japonica). Poultry Science, Champaign, v. 82, n. 7, p. 1188-1192, 2003.

HOCKING, P. M. Influence of the male on the decline of fertility with age in broiler breeder flock. In: BRILLARD, J. P. Control of Fertility in Domestic Birds. Nouzilly, INRA, 1990. p. 213-219.
HOWARTH, B. Carbohydrate involvement in sperm-egg interaction in the chicken. Journal of Receptor Research, New York, v. 12, n. 2, p. 255-265, 1992.

HUDSON, B. P.; DOZIER III, W. A.; WILSON, J. L.; SANDER, J. E.; WARD, T. L. Reproductive performance and immune status of caged broiler breeder hens provided diets supplemented with either inorganic or organic sources of zinc from hatching to $65 \mathrm{wk}$ of age. Journal of Applied Poultry Research, Athens, v. 13, n. 2, p. 349359, 2004.

KIDO, S.; DOI, Y. Separation and properties of the inner and outer layers of the vitelline membrane of hens' eggs. Poultry Science, Champaign, v. 67, n. 3, p. 476-486, 1988.

KING, A. S. Aparelho urogenital das aves. In: GETTY, R. SISSON/GROSSMAN - anatomia dos animais domésticos. 5. ed. Rio de Janeiro: Interamericana, v. 2, 1981. p. 1798-1839.

KOSIN, L. I. The accuracy of the macroscopic method in identifying fertile unincubated germ discs. Poultry Science, Champaign, v. 24, n. 3, p. 281-295, 1945.

LAKE, P. E. Recent progress in poultry reproduction. Worlds Poultry Science Journal, Columbus, v. 45, n. 1, p. 53-59, 1989.

LEESON, S.; SUMMERS, J. D. Broilers breeder production. Guelph: University Books, 2000. 334p.

MAIORKA, A. Efeito da idade da matriz e do Agente trófico (glutamina) sobre o desenvolvimento da mucosa intestinal e atividade enzimática do pâncreas de pintos de corte na primeira semana. 2002. Tese (Doutorado em Zootecnia) - Universidade Estadual Paulista, Jaboticabal.

MONTGOMERY, D. C. Introduction to statistical quality control. 2. ed. Canadá: John Wiley and Sons, 1991.

NATIONAL RESERCH COUNCIL - NRC. Nutrient requirements of poultry. $9^{\text {th }}$ ed. Washington: National Academy of Sciences, 1994. p. 155.

NOWACZEWSKI, S.; KONTECKA, H.; ROSIÑSKI, A.; KOBERLING, S.; KORONOWSKI, P. Egg quality of Japanese quail depends on layer age and storage time. Folia biologica, Kraków, v. 58, n. 3, p. 201-207, 2010.

OKAMURA, F.; NISHIYAMA, H. The passage of spermatozoa through the vitelline membrane in the domestic fowl. Gallus gallus. Cell and Tissue Research, Berlin, v. 188, n. 3, p. 497-508, 1978. 
PEDROSO, A. A.; CAFÉ, M. B.; LEANDRO, N. S. M.; STRINGHINI, J. H.; CHAVES, L. Desenvolvimento embrionário e eclodibilidade de ovos de codornas armazenados por diferentes períodos e incubados em umidades e temperaturas distintas. Revista Brasileira de Zootecnia, Viçosa, v. 35, n. 6, p. 2344-2349, 2006.

PROUDFOOT, F. G.; HULAN, H. W.; MCRAE, K. B. Effect old hatching egg size from semi-dwarf and normal maternal meat parent genotypes on the performance of broiler chickens. Poultry Science, Champaign, v. 61, n. 4, p. 655-660, 1982.

RABBANI, M. G.; SASANAMI, T.; MORI, M.; YOSHIZAKI, N. Characterization of the spermassociated body and its role in the fertilization of the chicken Gallus domesticus. Development, Growth and Differentiation, Nagoya, v. 49, n. 1, p. 39-48, 2007.

REIS, L. H.; GAMA, L. T.; SOARES, M. C. Effects of short conditions and broiler breeder age on hatchability, hatching time, and chick weights. Poultry Science, Champaign, v. 76, n. 11, p. 1459-1466, 1997.

ROBINSON, F. E.; HARDIN, R. T.; ROBBLEE, A. R. Reproductive senescence in domestic fowl: effects on egg production, sequence length, and inter-sequence pause length. Brazilian Journal of Poultry Science, Campinas, v. 31, n. 4, p. 871-879, 1990.

ROCHA JÚNIOR, J. M.; BAIÃO, N. C. Características físicas do sêmen de galos de matriz pesada com 35 e 68 semanas de idade. Arquivo Brasileiro de Medicina Veterinária e Zootecnia, Belo Horizonte, v. 53, n. 6, p. 683-685, 2001.

SANTOS, T. C.; MURAKAMI, A. E.; FANHANI, J. C.; OLIVEIRA, C. A. Production and reproduction of egg- and meat type quails reared in different group sizes. Brazilian Journal of Poultry Science, Campinas, v. 13, n. 1, p. 01-06, 2011.

SANTOS, T. C.; MURAKAMI, A. E.; OLIVEIRA, C. A. L.; GIRALDELLI, N. Sperm-egg interaction and fertility of Japanese breeder quails from 10 to 61 weeks. Poultry Science, Champaign, v. 92, n. 1, p. 205-210, 2013.
SAS Institute. 2009. SAS/STAT User's guide: release 9. 2. ed. SAS Inst. Inc., Cary, NC.

SILVERSIDES, F. G.; SCOTT, T. A. Effect of storage and layer age on quality of eggs from two lines of hens. Poultry Science, Champaign, v. 80, n. 8, p. 1240-1245, 2001.

SITTMANN, K.; ABPLANALP, H. Duration and recovery of fertility in Japanese quail (Coturnix coturnix japonica). British Poultry Science, Edinburgh, v. 6, n. 3, p. 245-250, 1965.

SULTANA, F.; MAO, K. M.; YOSHIZAKI, N. Possible involvement of a sperm-associated body in the process of fertilization in quail. Zoological Science, Tokyo, v. 21, n. 8, p. 851-858, 2004.

VIEIRA, R. S. A.; BERTECHINI, A. G.; FIALHO, E. T.; DOS SANTOS, C. D.; TEIXEIRA, A. S. Desempenho e qualidade de ovos de poedeiras comerciais de segundo ciclo alimentadas com rações contendo fitase. Ciência Agrotecnologia, Lavras, v. 25, n. 6, p. 1413-1422, 2001.

WILSON, H. R.; PIESCO, N. P.; MILLER, E. R.; NESBETH, W. G. Prediction of the fertility potential of broiler breeder males. World's Poultry Science Journal, Columbus, v. 35, n. 2, p. 95-118, 1979.

WISHART, G. J. Quantitative aspects of sperm:egg interaction in chickens and turkeys. Animal Reproduction Science, Amsterdam, v. 48, n. 1, p. 8 1-92, 1997.

Regulation of the length of the fertile period in the domestic fowl by numbers of oviducal spermatozoa, as reflected by those trapped in the laid eggs. Journal of Reproduction and Fertility, Colchester, v. 80, n. 2, p. 493-498, 1987.

WISHART, G. J.; STAINES, H. J. Measuring sperm:egg interaction to assess breeding efficiency in chickens and turkeys. Poultry Science, Champaign, v. 78, n. 3, p. 42836, 1999. 
